\title{
STUDI PENEMPATAN KAPASITOR EKSITASI PADA GENERATOR INDUKSI SATU FASA
}

\author{
Rahmat Hidayat, Refdinal Nazir \\ Program Studi Teknik Elektro, Fakultas Teknik \\ Universitas Andalas
}

\begin{abstract}
ABSTRAK - Motor induksi satu fasa hanya dapat beroperasi sebagai generator induksi satu fasa eksitasi sendiri (SPSEIG) jika rotornya diputar diatas kecepatan sinkron, serta kumparan bantu dan/atau kumparan utama dihubungkan kapasitor eksitasi. Paper ini menganalisis pengaruh penempatan kapasitor eksitasi terhadap performansi dari SPSEIG, yang meliputi: tegangan dan frekuensi generator. Hasil simulasi komputer dibandingkan dengan hasil pengujian laboratorium untuk menguji keakuratan model dan metode analisis yang diajukan. Berdasarkan hasil pengujian dan simulasi, penggunaan dua buah kapasitor eksitasi yang dipasang di kumparan utama dan kumparan bantu menghasilkan performansi paling baik dari kestabilan tegangan dan frekuensi. Penggunaan satu kapasitor eksitasi di kumparan utama akan menyebabkan drop tegangan relatif lebih besar ketika dibebani.
\end{abstract}

\section{Kata Kunci :SPSEIG, kapasitor eksitasi, kumparan utama, kumparan bantu, matrik admitansi}

\begin{abstract}
Single phase induction motor can only operate as a single-phase self-excited induction generator (SPSEIG) when the rotor is rotated above synchronous speed, as well as auxiliary windings and / or main windings is connected capacitor excitation. This paper analyzes the influence of the placement of excitation capacitor on the performance of SPSEIG, which include: voltage and frequency generator. Computer simulation results compared with the results of laboratory testing to verify the accuracy of the models and methods of analysis are proposed. Based on test results and simulation, the use of two capacitors excitation coil mounted in the main and auxiliary windings produce best performance of voltage and frequency stability. The use of a capacitor excitation in the main windings will cause relatively high voltage drop when loaded.
\end{abstract}

Keywords :SPSEIG,excitation capacitor,main windings, auxiliary windings, admitance matrix

\section{Daftar Simbol}

\begin{tabular}{clll} 
Simbol & \multicolumn{1}{c}{ Keterangan } & $\mathrm{X}_{1 U}$ & Reaktansi stator kumparan utama (p.u.) \\
$n_{s}$ & Kecepatan sinkron (pu) & $\mathrm{X}_{1 B}$ & Reaktansi stator kumparan bantu (p.u.) \\
$n_{r}$ & Kecepatan rotor (pu) & $\mathrm{X}_{2}$ & Reaktansi rotor (p.u.) \\
$\mathrm{S}$ & Slip & $\mathrm{X}_{L}$ & Reaktansi beban (p.u.) \\
$F$ & Frekuensi per unit (p.u.) & $\mathrm{X}_{m}$ & Reaktansi magnetisasi (p.u.) \\
$U$ & Kecepatan per unit (p.u.) & $\mathrm{V}_{T}$ & Tegangan terminal beban (p.u.) \\
a & Rasio lilitan kumparan bantu terhadap & $\mathrm{V}_{g}$ & Tegangan celah udara generator (p.u.) \\
$\mathrm{X}_{\mathrm{Clsh}}$ & $\begin{array}{l}\text { kumparan utama } \\
\text { Reaktansi Kapasitor eksitasi paralel di }\end{array}$ & $I_{s f}$ & Arus stator kumparan utama komponen \\
$\mathrm{X}_{\mathrm{sh}}$ & $\begin{array}{l}\text { Reaktansi kapasitor eksitasi paraleldi } \\
\text { kumparan bantu (p.u.) }\end{array}$ & $I_{s b}$ & $\begin{array}{l}\text { Arus stator kumparan utama komponen } \\
\text { mundur (p.u.) }\end{array}$ \\
$R_{1 U}$ & $\begin{array}{l}\text { Resistansi stator kumparan utama } \\
\text { (p.u.) }\end{array}$ & $I_{S}$ & Arus stator (p.u.) \\
$R_{1 B}$ & $\begin{array}{l}\text { Resistansi stator kumparan bantu } \\
\text { (p.u.) }\end{array}$ & $I_{B}$ & Arus kumparan bantu (p.u.) \\
$R_{L}$ & Beban resistif (p.u.) & $I_{C}$ & Arus kapasitor kumparan utama (p.u.) \\
$R_{2}$ & Resistansi rotor (p.u.) & $I_{L}$ & Arus beban (p.u.)
\end{tabular}




\section{PENDAHULUAN}

Belakangan ini, penggunaan generator induksi sebagai pembangkit listrik dengan sumber energi terbarui semakin meningkat. Hal ini disebabkan karena beberapa keunggulannya dibandingkan dengan generator konvensional, diantaranya adalah: pengoperasian dan pemeliharaannya sederhana, tanpa sikat, harga lebih murah, mampu mengatasi gangguan dengan proteksi sendiri dan sanggup membangkitkan daya pada kecepatan bervariasi. Selain itu, penggunaan generator induksi pada pembangkit listrik dengan kapasitas kecil seperti pada pembangkit listrik mikrohidro (PLTMH) lebih menguntungkan dibandingkan menggunakan generator sinkron [1].

Salah satu aplikasi generator induksi ini dapat dioperasikan pada kondisi berdiri sendiri /terisolasi untuk penyediaan energi listrik daerah terpencil [2]. Di daerah terpencil dimana distribusi penduduknya relatif jarang, umumnya menggunakan suplai listrik satu fasa. Suplai satu fasa lebih cocok digunakan karena pembuatan sistem distribusinya sederhana dan biayanya murah [3]. Salah satu cara untuk mendapatkan generator induksi 1 fasa adalah mengubah motor induksi 1 fasa menjadi generator induksi dengan cara memberikan suplai daya reaktif ke dalam motor induksi [4]. Motor induksi satu fasa dapat beroperasi sebagai Single Phase Self Excitation Induction Generator (SPSEIG) jika rotornya diputar diatas kecepatan sinkron dan antara kumparan utama dengan kumparan bantu dipisahkan secara listrik, yang terdapat kapasitor eksitasi pada salah satu atau kedua kumparan ini [5].

Leicht dan Makowski [5] berhasil melakukan simulasi pengaruh topologi kapasitor dan jumlah lilitan kumparan stator terhadap performa SPSEIG. Kim dan Lee [6] berhasil mengitung nilai kapasitor eksitasi di kumparan bantu pada SPSEIG. Lalwani dan Singh [2] menganalisis SPSEIG dengan satu kumparan dalam kondisi mantap. Berbagai metode telah digunakan untuk analisis SPSEIG dalam kondisi matap,seperti: Newton Raphson, logika fuzzy dan algoritma genetika pada SPSEIG [7-9]. Gurung dan Freere [10] menganalisis generator induksi tiga fasa dengan teknik komputasi matlab simbolik.

Dalam tulisan ini dianalisis penempatan kapasitor eksitasi pada SPSEIG. Analisis inii digunakan untuk menentukan penempatan kapasitor eksitasi yang efektif dari SPSEIG, agar diperolah performansinya terbaik. Dalam dalam analisis ini digunakan metode MATLAB symbolic computation.

Tulisan ini terdiri dari 5 bagian. Bagian ke 2 membahas tentang pemodelan dari SPSEIG. Metode yang digunakan dibahas pada bagian ke 3 , sedangkan hasil dan pembahasan didiskusikan pada bagian ke 4 serta kesimpulan di bagian ke 5.

\section{PEMODELAN}

Dua jenis konfigurasi SPSEIG yang dibandingkan dalam paper adalah :

1. SPSEIG dengan kapasitor eksitasi terpasang paralel di kumparan utama dan kumparan bantu (Konfigurasi-1)

2. SPSEIG dengan kapasitor eksitasi terpasang paralel di kumparan utama (Konfigurasi-2)

\subsection{Konfigurasi-1}

Rangkaian ekivalen SPSEIG dengan kapasitor eksitasi terpasang paralel di kumparan utama dan kumparan bantu ditunjukan oleh Gambar 1. Parameter- parameter rangkaian ekivalen adalah sebagai berikut:

$$
\begin{aligned}
& Z_{1}=R_{L}+j F X_{L} \\
& Z_{2}=\frac{-j X_{C L s h}}{F} \\
& Z_{3}=-\frac{R_{L}}{2}-\frac{j F X_{L}}{2} \\
& Z_{4}=\frac{j X_{C L s h}}{2 F} \\
& Z_{5}=R_{L}+j F X_{L} \\
& Z_{6}=\frac{-j X_{C L s h}}{F} \\
& Z_{7}=j F X_{m} \\
& Z_{8}=j F X_{2}+\frac{R_{2} F}{F-U} \\
& Z_{9}=j F X_{m} \\
& Z_{10}=j F X_{2}+\frac{R_{2} F}{F+U} \\
& Z_{11}=R_{1 U}+j F X_{1 U}
\end{aligned}
$$




$$
\begin{aligned}
& Z_{12}=R_{1 U}+j F X_{1 U} \\
& Z_{13}=\frac{R_{1 B}}{2 a^{2}}+\frac{j F X_{1 B}}{2 a^{2}}-\frac{j X_{s h}}{2 F a^{2}}-\frac{R_{1 U}}{2}-\frac{j F X_{1 U}}{2}
\end{aligned}
$$

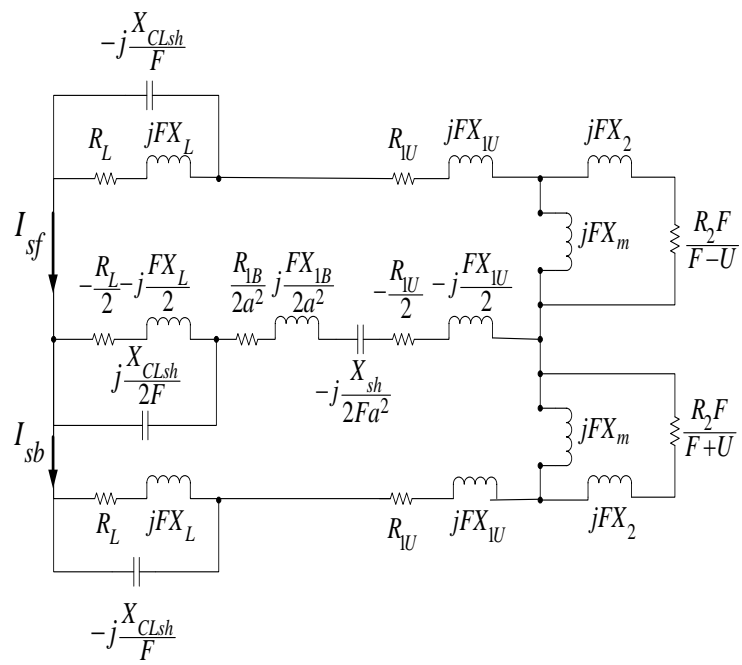

Gambar 1. Rangkaian ekivalen SPSEIG dengan Konfigurasi-1

Persamaan matrik admitansi berdasarkan rangkaian ekivalen Gambar 1 adalah:

$$
\left(\begin{array}{ccc}
Y_{7}+Y_{8}+Y_{U} & -\left(Y_{7}+Y_{8}\right) & 0 \\
-\left(Y_{7}+Y_{8}\right) & Y_{7}+Y_{8}+Y_{9}+Y_{10}+Y_{V} & -\left(Y_{9}+Y_{10}\right) \\
0 & -\left(Y_{9}+Y_{10}\right) & Y_{9}+Y_{10}+Y_{W}
\end{array}\right)\left(\begin{array}{l}
V 1 \\
V 2 \\
V 3
\end{array}\right)=\left(\begin{array}{l}
0 \\
0 \\
0
\end{array}\right)
$$

atau

$$
[Y] \cdot[V]=0
$$

Performansi mesin diperoleh dari persamaanpersamaan berikut :

$$
D=\left(\left(Z_{U}+Z_{V}\right)\left(Z_{U}+Z_{V}\right)\right)-Z_{V}{ }^{2}
$$

Arus kumparan utama komponen maju yaitu:

$$
\boldsymbol{I}_{s f}=\frac{\frac{V_{g f}}{F}\left(Z_{U}+Z_{V}+Z_{10}\right)}{D}
$$

Arus kumparan utama komponen mundur yaitu

$$
\boldsymbol{I}_{s b}=V_{g f} \frac{Z_{V}}{D . \mathrm{F}}
$$

Arus yang mengalir di kumparan utama yaitu

$$
\boldsymbol{I}_{S}=\boldsymbol{I}_{s f}+\boldsymbol{I}_{s b}
$$

Arus yang mengalir di kumparan bantu

$$
\boldsymbol{I}_{B}=j\left(\boldsymbol{I}_{s f}-\boldsymbol{I}_{s b}\right)
$$

Tegangan terminal beban kumparan utama yaitu

$$
\boldsymbol{V}_{T} \quad=\boldsymbol{I}_{L} \cdot\left(R_{L}+j F X_{L}\right)
$$

Daya keluaran generator yaitu

$$
P_{\text {output }}=I_{L}^{2} \cdot R_{L}
$$

\subsection{Konfigurasi-2}

Rangkaian ekivalen SPSEIG dengan kapasitor eksitasi terpasang paralel di kumparan utama dan kumparan bantu ditunjukan oleh Gambar 2. Parameter-parameter rangkaian ekivalen didefenisikan sebagai berikut :

$$
\begin{aligned}
& Z_{1}=\frac{R_{L}}{F}+j X_{L} \\
& Z_{2}=\frac{-j X_{C L s h}}{F^{2}} \\
& Z_{3}=\frac{R_{1 U}}{F}+j X_{1 U} \\
& Z_{4}=\frac{R_{2}}{2(F-U)}+\frac{j X_{2}}{2} \\
& Z_{5}=\frac{R_{2}}{2(F+U)}+j \frac{X_{2}}{2} \\
& Z_{6}=j \frac{X_{m}}{2}
\end{aligned}
$$

Persamaan matrik admitansi berdasarkan rangkaian ekivalen Gambar 2 adalah:

$$
\begin{aligned}
& \left(\begin{array}{ccc}
Y_{1}+Y_{2}+Y_{3} & -\left(Y_{3}\right) & 0 \\
-\left(Y_{3}\right) & Y_{3}+Y_{4}+Y_{6} & -\left(Y_{4}+Y_{6}\right) \\
0 & -\left(Y_{4}+Y_{6}\right) & Y_{4}+Y_{5}+Y_{6}
\end{array}\right)\left(\begin{array}{l}
V 1 \\
V 2 \\
V 3
\end{array}\right)=\left(\begin{array}{l}
0 \\
0 \\
0
\end{array}\right) \\
& {[Y] \cdot[V]=0}
\end{aligned}
$$

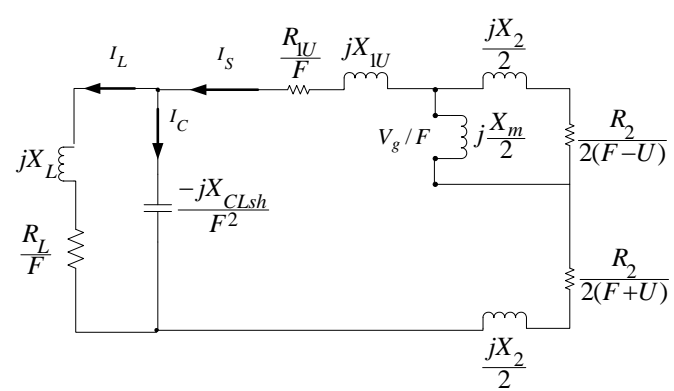

Gambar 2. Rangkaian ekivalen SPSEIG untuk konfigurasi-2

Performansi mesin diperoleh dari persamaan persamaan berikut: 
Arus di kumparan utama

$$
\boldsymbol{I}_{S}=\frac{V_{g f} / F}{\frac{\mathrm{R}_{I U}}{F}+j X_{I U}+\frac{R_{2}}{2(F+U)}+j \frac{X_{2}}{2}+\left(\frac{F X_{L} X_{C s b}-j X_{C l s h} R_{L}}{R_{L} F^{2}-j F\left(X_{C s b h}+X_{L}\right)}\right)}
$$

Sekarangnilai $I_{L}$ dan $I_{C}$ bisa dihitung

$$
\begin{aligned}
& I_{L}=\frac{F X_{L} X_{C l s h}-j X_{C s s h} R_{L}}{R_{L}^{2} F+j X_{L} R_{L} F^{2}-j R_{L}\left(X_{C s h}+X_{L}\right)+F\left(X_{C s h}+X_{L}\right) X_{L}} \times I_{S} \\
& I_{C}=I_{S}-I_{L}
\end{aligned}
$$

Tegangan terminal bebankumparanutama

$V_{T}=I_{L} \cdot R_{L}$

Daya output

$$
P_{\text {out }}=I_{L}^{2} \cdot R_{L}
$$

\section{METODE ANALISIS}

Spesifikasi mesin induksi satu fasa yang digunakan pada kajian ini ditunjukan pada tabel 1. Pada konfigurasi-1 menggunakan dua buah kapasitor eksitasi yang paralel di kumparan utama yaitu $51,2 \mu \mathrm{F}$ dan $12 \mu \mathrm{F}$ di kumparan bantu, sedangkan pada konfigurasi-2 hanya menggunakan kapasitor eksitasi paralel di kumparan utama yaitu $71,2 \mu \mathrm{F}$ sedangkan kumparan bantu di buka (open circuit).

Tabel 1. Spesifikasi mesin induksi yang digunakan

\begin{tabular}{|l|l|}
\hline \multicolumn{2}{|c|}{ Type 73 204 Class 0.3} \\
\hline $230 \mathrm{~V}$ & $2.5 \mathrm{~A}$ \\
\hline $0.37 \mathrm{~kW}$ & Cos $\varphi 0.98$ \\
\hline $50 \mathrm{~Hz}$ & $1435 \mathrm{RPM}$ \\
\hline $\mathrm{CA}=50-60 \mathrm{uF}$ & $\mathrm{CB}=20 \mathrm{uF}$ \\
\hline Is $: \mathrm{F}$ & $\mathrm{IP}: 20$ \\
\hline
\end{tabular}

Tabel 2. Parameter mesin induksi yang direferensikan ke kumparan utama

\begin{tabular}{|l|l|l|}
\hline \multirow{2}{*}{ Parameter } & \multicolumn{2}{|c|}{ Satuan } \\
\cline { 2 - 3 } & \multicolumn{1}{|c|}{ Ohm } & \multicolumn{1}{c|}{ p.u. } \\
\hline $\mathrm{R}_{1 \mathrm{U}}$ & 7.2 & 0.078 \\
\hline $\mathrm{X}_{1 \mathrm{U}}$ & 10.33 & 0.112 \\
\hline $\mathrm{R}_{1 \mathrm{~B}}$ & 18.5 & 0.2010 \\
\hline $\mathrm{X}_{1 \mathrm{~B}}$ & 22.3606 & 0.2430 \\
\hline $\mathrm{R}_{2}$ & 10.43 & 0.1133 \\
\hline $\mathrm{X}_{2}$ & 10.33 & 0.112 \\
\hline \multicolumn{3}{|c|}{$\mathrm{a}=1,4357$} \\
\hline
\end{tabular}

\section{Metode Analisis Rangkaian Menggunakan MATLAB Symbolic Computation}

Pada saat generator beroperasi $[V] \neq 0$ maka $\operatorname{det}[Y]=0$. Ini berarti komponen real dan imajiner dari $\operatorname{det}[Y]$ bernilai nol.

Real $\operatorname{det}[Y]=0$

Imajiner $\operatorname{det}[Y]=0$

Dengan memasukan kecepatan rotor, parameter generator, reaktansi kapasitor eksitasi, dan impedansi beban, maka nilai frekuensi output (F) dalam p.u. dan nilai reaktansi magnetisasi $\left(X_{m}\right)$ dapat diperoleh dengan menyamakan komponen real dan imajiner admitansi total $=0$.

Dengan metode konvensional biasanya akan diperoleh dua persamaan polinomial orde tinggi sehingga untuk menyelesaikannya akan membutuhkan manipulasi matematika untuk mendapatkan nilai koefisiennya dan itu akan memakan waktu yang lama. Pada metode ini kita tidak perlu melakukan penyederhanaan persamaan dan mengunakan metode numerik untuk menyelesaikan variabel yang belum diketahui. Kita hanya perlu membuat persamaan matriks admitansinya dalam bentuk simbol aljabar di matlab, dan selanjutnya diselesaikan dengan fungsi kunci MATLAB berikut ini:

\section{S = solve(real,imajiner) \\ $\mathrm{S}=[\mathbf{S . F}$ S.Xm]}

Setelah nilai $\mathrm{F}$ dan $X_{m}$ diketahui maka nilai tegangan pada celah udara $V_{g}$ dapat ditentukan menggunakan kurva magnetisasi yang secara matematis dapat ditulis sebagai berikut;

$V_{g}=-0,034 X_{m}{ }^{3}+4,673 X_{m}{ }^{2}-217,9 X_{m}+3676$

Untuk $36 \leq X_{m} \leq 59$ 


\section{HASIL DAN PEMBAHASAN}

\section{Pengaruh Beban Terhadap Tegangan Terminal dan Frekuensi}
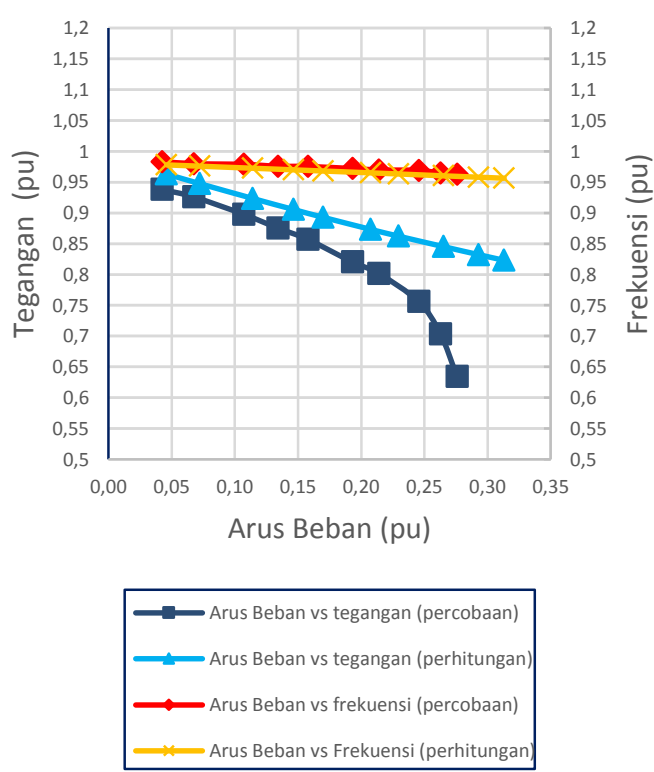

Gambar 3. Hasil untuk konfigurasi-1

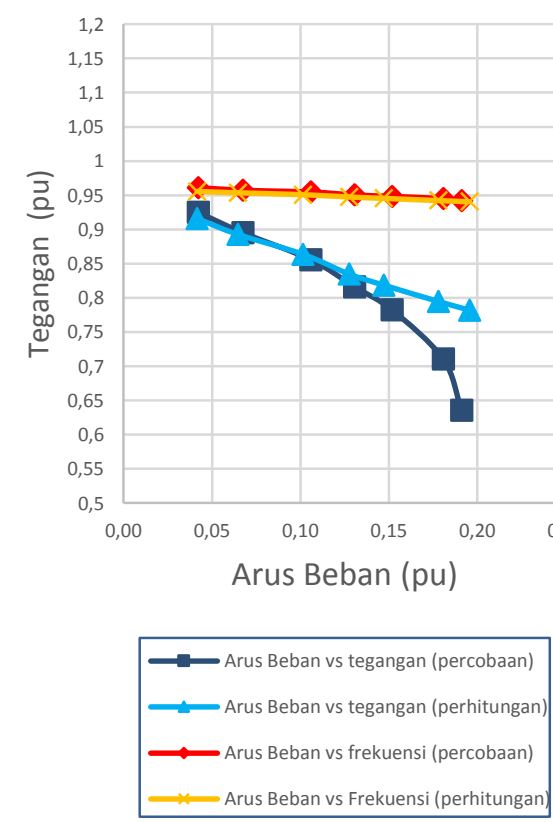

Gambar 4. Hasil untuk konfigurasi-2

Dari Gambar 3 dan Gambar 4 dapat dianalisis bahwa saat beban meningkat maka nilai tegangan akan turun. Hal yang sama juga terjadi pada nilai frekuensinya yang juga ikut turun.
Pada konfigurasi-1, hasil pengujian menunjukkan nilai tegangan berkisar antara 0.938 p.u - 0.634 p.u (tegangan dasar 230 volt), sedangkan hasil simulasi menunjukkan nilainya berkisar antara 0.963 p.u -0.823 p.u. Sementara pada konfigurasi-2, hasil pengujian menunjukan nilai tegangan lebih rendah dari konfigurasi-1 yaitu berkisar antara 0.924 p.u -0.635 p.u. dan secara simulasi nilainya berkisar antara 0.915 p.u -0.781 p.u.

Dari segi frekuensi, pada konfigurasi-1, hasil pengujian nilainya berkisar antara 0.983 p.u 0,963 p.u. (frekuensi dasar $50 \mathrm{~Hz}$ ) dan secara simulasi yaitu 0,978 p.u - 0,956 p.u. Sedangkan pada konfigurasi-2 hasil pengujian juga menunjukan nilai frekuensi lebih rendah dari konfigurasi-1 yakni nilainya berkisar antara 0.961 p.u - 0,941 p.u dan secara simulasi yaitu 0,955 p.u $-0,940$ p.u

\section{Pengaruh Kecepatan Terhadap Tegangan Terminal Beban dan Frekuensi}

Dari Gambar 5 dan Gambar 6 terlihat bahwa baik hasil pengujian maupun simulasi, tegangan dan frekuensi akan naik ketika kecepatan rotor meningkat. Pada konfigurasi1,hasil pengujian menunjukkan nilai frekuensi 1.0 p.u. diperoleh pada kecepatan 1.02 p.u( kecepatan dasar $1500 \mathrm{rpm}$ ), sedangkan secara simulasi diperoleh pada kecepatan $1.023 \mathrm{pu}$.

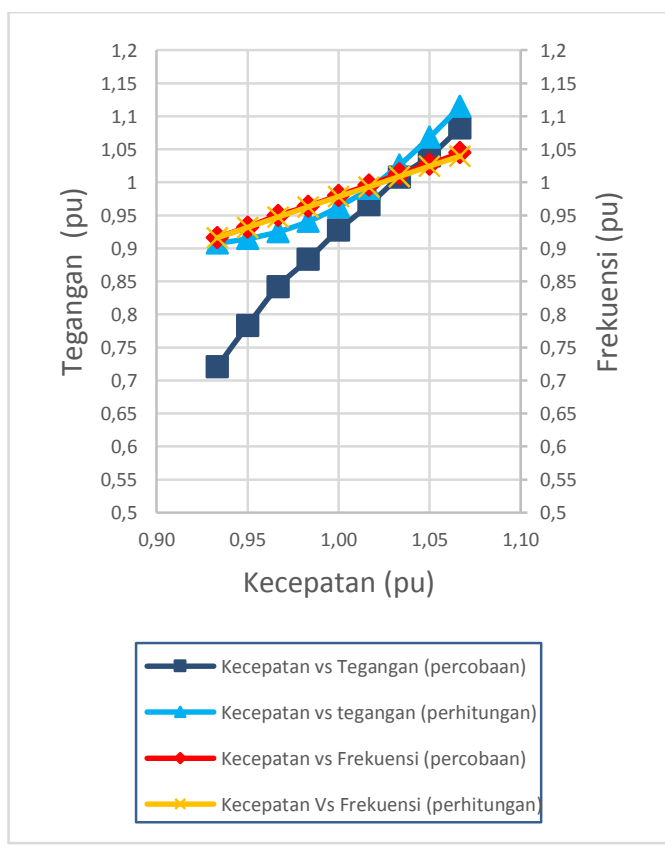

Gambar 5. Hasil untuk konfigurasi-1 


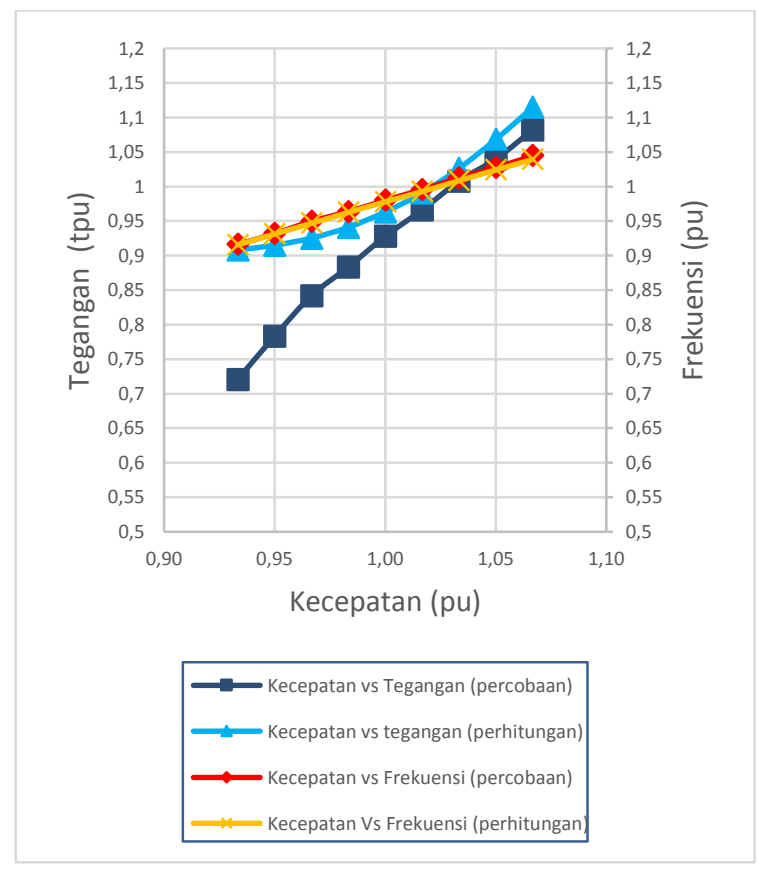

Gambar 6.Hasil untuk konfigurasi-2

Untuk konfigurasi-2, hasil pengujian menunjukkan nilai frekuensi $1.0 \mathrm{pu}$ diperoleh pada kecepatan $1.0453 \mathrm{pu}$, sedangkan secara simulasi diperoleh pada kecepatan $1.0533 \mathrm{pu}$.

\section{KESIMPULAN}

Dari hasil pengujian dan simulasi dapat disimpulkan bahwa tegangan dan frekuensi generator pada konfigurasi-1 lebih stabil daripada menggunakan konfigurasi-2, sehingga penempatan kapasitor eksitasi paling efektif adalah menggunakan dua buah kapasitor eksitasi yang letaknya satu paralel di kumparan utama dan satu lagi paralel di kumparan bantu.

\section{DAFTAR PUSTAKA}

[1] Khusuma, Andre. Perancangan Dan Pembuatan Alat Kompensasi Seri Generator Induksi Dengan Metode Modulasi Lebar Pulsa. Tugas Akhir. Universitas Andalas : Padang. 2003.

[2] Mahendra Lalwani dan Mool Singh,"Analysis of Single Phase SelfExcited Induction Generator with One Winding for Obtaining Constant Output Voltage",International Journal of Electrical Engineering. ISSN 0974-2158 Volume 4, Number 2 (2011), pp.173-181.
[3] S.N.Mahato, S.P.Singh, dan M.P.Sharma,"Capasitor Required For Maximum Power Of A Self- Excited Single-Phase Induction Generator Using A Three Phase Machine",IEEE Transaction on Energy Conversion, Vol. 23, No.2, Juni 2008.

[4] Effendy, Machmud. Rancang Bangun Motor Induksi Sebagai Generator (Misg) Pada Pembangkit Listrik Tenaga Mikrohidro. Jurnal Teknik Elektro, Volume 11, Nomor 2, Juni 2009, hal 7176.

[5] Aleksander Leicht dan Krzysztof Makowski, "A single-phase induction motor operating as a self-excited induction generator", Archives Of Electrical Engineering Vol. 62(3), pp. 361-373 (2013).

[6] Cherl-jin Kim dan Kwan-Yong Lee," A Study on the Modelling and Design of Single Phase Induction Generators", KIEE International Transaction on Electrical Machinery and Energy Convertion System, Vol.5-B, No. 4, pp. 331-336, 2005.

[7] Y.H.A. Rahim, A.I. Alolah dan R.I. AlMudaiheem, "Performance of Single Phase Induction Generators", IEEE Transaction on Energy Conversion, Vol. 8, No. 3, September 1993.

[8] S. Singaravelu dan G. Balasubramanian, "Dynamic and Steady-State Analysis of Self-ExcitedSingle-Phase Two-Winding Induction Generators",International Journal of Computer Applications (0975 8887)Volume 53- No.12, September 2012.

[9] S.Sasikumar, S.Singaravelu, "Genetic Algorithm based Steady State Analysis of Single-phase Self-excited Induction Generators", International Journal of Computer Technology and Electronics Engineering(IJCTEE) Volume 2, Issue 2, April 2012.

[10] Gurung K., Freere P,"Matlab Symbolic Computation For The Steady State ModelingOf Symmetrically Loaded Self Excited Induction Generator", Kathmandu University Journal Of Science, Engineering And Technology Vol.I, No. III, January, 2007. 


\section{Biodata Penulis}

Rahmat Hidayat, lahir 10 februari 1992 di Sumani. Merupakan alumni asisten Laboratorium Konversi Energi Elektrik Jurusan Teknik Elektro Universitas Andalas. Telah menyelesaikan Program Strata-1 pada Jurusan Teknik Elektro pada bulan oktober 2014.

\section{Refdinal Nazir}

Dosen Jurusan Teknik Elektro Unand Bidang Konversi Energi Listrik. Spesifikasi keahlian: mesin-mesin listrik, energi terbarukan, mikrogrid. 